\title{
Mismatch negativity effects of alternating vowels in morphologically complex word forms
}

\author{
Mathias Scharinger ${ }^{\mathrm{a}, \mathrm{b}, *}$, Aditi Lahiri ${ }^{\mathrm{c}, \mathrm{b}}$, Carsten Eulitz ${ }^{\mathrm{b}}$

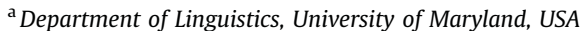 \\ ${ }^{\mathrm{b}}$ Department of Linguistics, University of Konstanz, Germany \\ ${ }^{c}$ Centre for Linguistics and Philology, University of Oxford, UK
}

\author{
A B S T R A C T
}

In some languages, morphologically complex word forms may involve vowel alternations between front and back phonemes, as illustrated in the German noun Stock (Stock Stöcke 'stick sticks') versus the non-alternating Stoff (Stoff Stoffe 'cloth cloths'). This study was aimed to investigate the consequences of the presence or absence of these alternations for the fine structure of lexical representations. Previous research has shown that certain vowel oppositions are processed in an asymmetric way, as studied by means of brain electric activity (e.g. Eulitz \& Lahiri, 2004). Here, we contrasted base form and diminutive stems of German nouns in a Mismatch Negativity (MMN) study. We compared the alternating noun Stock with non-alternating Stoff and obtained a consistently stronger MMN if Stoff was preceded by a fronted stem. This was an initial stem fragment in Experiment 1 and its diminutive form in Experiment 2. The results of our experiments indicate asymmetries in processing at the phonetics/morpho-phonology interface and are discussed on the background of several models of lexical representation and morphological processing. We conjecture that our findings are best explained by differences in abstract phonological representations.

* Corresponding author. Department of Linguistics, 1401 Marie Mount Hall, University of Maryland, College Park, MD 20742-7505, USA. Tel.: +1 3014053127.

E-mail address: mts@umd.edu (M. Scharinger). 


\section{Introduction}

Regular and irregular morphological processes have been of particular interest in psycholinguistic and neurolinguistic research. Arising from an apparently simple and clear-cut distinction between regular (rule-based) and irregular (memory-based) operations, models either implement this distinction directly into their processing and representation architecture, or they try to account for the morphological distinction by different means. Models of the former kind have become known as Dual Mechanism or Dual Route approaches (e.g. Baayen, Dijkstra, \& Schreuder, 1997; Clahsen, 2006; Clahsen, Eisenbeiss, Hadler, \& Sonnenstuhl, 2001; Clahsen, Eisenbeiss, \& Sonnenstuhl-Henning, 1997; Pinker, 1991, 1998; Pinker \& Prasada, 1993; Schreuder \& Baayen, 1997). Their basic assumption is that regular processes - such as the attachment of the past tense suffix /-ed/ in English - are handled by a symbol processor, while irregular forms defy these symbolic rules, since they usually involve arbitrary stem alternations (sing sang) without invoking the regular past tense suffix. These forms are assumed to be represented as separate stems. Nevertheless, the opposition of the two distinct vowels [I] and [æ] on the phonetic level must be resolved during the processing of these irregular forms. It is precisely this vowel alternation at the interface of phonetics/phonology and morphology that is the focus of our research reported here. Native speakers of English process the difference between [I] and [æ] in the stems sing and sang such that one denotes a musical event in the present and the other one a musical event in the past. How does this low-level difference interact with higher-order processes, in particular, with morphological processing? And how are stem alternations coded in the mental lexicon?

A particular suitable language for our objectives is German, where these alternations are abundant and have a (semi) regular status. Methodologically, we opted for an electrophysiological assessment of the vowel change perception, namely, the Mismatch Negativity (MMN), which we consider very suitable for our purposes: It is primarily sensitive to the detection of acoustic change (Näätänen \& Alho, 1997), but also taps into higher-order processes (Menning et al., 2005; Pulvermüller \& Shtyrov, 2006).

\section{Vowel alternations in German}

Similar to English, German has regular and irregular morphological processes. Other than in English, however, a strict alignment of regularity and affixed-based morphology is less obvious (cf. Smolka, Zwitserlood, \& Rösler, 2007). Stem alternations are especially productive and semi-regular in German nouns with back vowels. These vowels are fronted in certain morphological categories, such as in the plural or in diminutive formations. The back vowels alternate with their fronted counterparts in a process referred to as umlaut (Wiese, 1987, 1996, 2000; Wurzel, 1984). For instance, the plural of the noun Stock (stick) with the stem vowel [o] is realized as Stöcke with the stem vowel [œ]. ${ }^{1}$

On the other hand, there are nouns with back vowels which do not alternate in the plural. For instance, the plural of Stoff (cloth) is Stoffe and both stems have the identical vowel [o]. Finally, there are nouns of which the stem vowel is front in the singular and does not alternate in the plural (Mönch Mönche 'monk monks', Bett Betten 'bed beds').

Umlaut occurs in many grammatical categories in German (Wurzel, 1984) and is irregular only insofar it does not apply to all stems with back vowels (e.g. Stoffe). It is considered semi-regular and even productive in the derivation of diminutive forms, which almost exclusively take an umlauted stem, independent of potential plural alternations (cf. Stöckchen 'little stick' vs. Stöffchen 'frazzle'). On the other hand, the umlaut alternation pertains to a phonemic contrast in German: All fronted counterparts of the back vowels exist as phonemes in the German vowel inventory. From a phonetic perspective, the contrast between [o] and [œ] is not allophonic and cannot be resolved on a phonetic level. Rather, whenever a listener encounters an umlauted stem as in Stöcke (sticks), there must be an

\footnotetext{
${ }^{1}$ Note that there is vowel quality difference between the short vowel in Stock (stick), which is transcribed as [o], and the long vowel in Strom (stream), which is transcribed as [o]. The same distinction is made for the front counterparts [œ] and [ø]. Note also that while there is an additional/-e/suffix in the examples provided in this paper, umlaut can also be the sole marker of plurality (e.g. Tochter $\sim$ Töchter 'daughter').
} 
alternative possibility to map or relate this stem to the singular stem with the back vowel [o]. We provide an account of how this can be achieved in General Discussion.

\section{The MMN as automatic change detection response}

A useful electrophysiological measure of acoustic deviance is the Mismatch Negativity (MMN), an automatic change detection response of the brain (Näätänen, 2001; Näätänen \& Alho, 1997; Näätänen, Paavilainen, Rinne, \& Alho, 2007; Winkler, 2007). It is elicited if a rare deviant stimulus occurs in a series of repetitious standard stimuli and does not require attentional processing of either standard or deviant (Näätänen, 1992). The MMN is also elicited by speech stimuli and has been shown to be of greater magnitude if the speech sounds belong to the native inventory of the listener (Näätänen \& Alho, 1997; Winkler et al., 1999). Further, the MMN also occurred in paradigms with words and affixes and has been interpreted as reflecting their memory traces (Pulvermüller et al., 2001; Shtyrov \& Pulvermüller, 2002a, 2002b). Finally, recent work suggested that the MMN is not only modulated by the magnitude of the deviant change (i.e. by the acoustic information) or the phonotactic probability in the stimulus material (Bonte, Mitterer, Zellagui, Poelmans, \& Blomert, 2005), but also by higher-order processes via top-down influences of syntactic or semantic information (Menning et al., 2005; Pulvermüller \& Shtyrov, 2006).

Regarding the opposition of the round mid vowels [0] and [œ] in German, Eulitz and Lahiri (2004) investigated the long counterparts [o] and [ø] in a single vowel MMN study. Intriguingly, their results showed an asymmetry based on the latency and amplitude of the MMN. If [ø] was the deviant after a series of [o], the MMN occurred earlier and with higher peak amplitudes than if [o] was the deviant after a series of [ø] standards. Eulitz \& Lahiri conjectured that this outcome reflected the differences in representation of the two vowels: While the back vowel has a more informative representation, the front vowel is underspecified for its place of articulation. The MMN then reflected the interaction of phonological representation and phonetic-acoustic feature extraction, as described by the matching algorithm of the Featurally Underspecified Lexicon (FUL, Lahiri \& Reetz, 2002b), to which we will turn in General Discussion.

Given the grammatical status of German umlaut and the previous findings from MMN studies, we were interested whether and how the MMN elicited by the acoustic-phonetic differences between front and back mid vowels could be modulated by morphological information. In particular, would we find MMN differences between alternating Stock and non-alternating Stoff if preceded by front vowel standards? Could this difference arise from the presence or absence of the stem vowel alternation in the plural?

\section{Experiment 1}

\subsection{Rationale}

In the first experiment, we were interested in the MMN response to [0] in the alternating stem Stock and the non-alternating stem Stoff if preceded by a standard with the front vowel [œ] as opposed to a standard with the back vowel [o]. We opted for initial CCV fragments taken from the back vowel singular stems (Sto- [ $[$ to]) and the front vowel diminutive stems (Stö- [ $[$ tœ]). These initial stem fragments enabled us to use standards which could be the beginnings of alternating Stock, non-alternating Stoff, or their corresponding diminutive forms. We expect differences in the MMN response between alternating Stock and non-alternating Stoff if preceded by the front vowel fragment Stö-. While in both cases, MMN responses should be elicited due to the acoustic opposition of a front vowel in standard and a back vowel in deviant position, the opposition ought to be anticipated for alternating Stock but not for non-alternating Stoff, since German native speaker have grammatical knowledge regarding the presence or absence of this stem alternation.

\subsection{Materials}

We recorded the minimally differing German words Stock and Stoff (stick, cloth) and their corresponding diminutive forms Stöckchen and Stöffchen (little stick, frazzle) from which we also took the 
initial stem fragments for Experiment 1. Note that full diminutive forms were only used in Experiment 2. The selection of the diminutives was motivated by the fact that fronted stems most consistently occur in this category. Further, as for Stoff, the diminutive comprises the only existing stem with a front vowel.

Regarding token bigram frequencies, the sequences of [ø]/[œ] and either [k] or [f] were similar (473 vs. 452), as were the sequences of [o]/[0] and either [k] or [f] (2929 vs. 2041, all numbers based on the CELEX German word form database; Baayen, Piepenbrock, \& Gulikers, 1995). A similar pattern was yielded by the log-values of the respective cumulative frequencies, reflecting estimates of phonotactic probabilities ([ok/ok] vs. [of/of]: 3.9 vs. 4.2 ; [øk/œk] vs. [øf/œf]: 3.3 vs. 3.6). The log-values of the Mannheim frequencies of the base forms were also comparable (Stock: 2.1, Stoff: 2.2). Finally, we assessed the typicality of our stimuli by a familiarity rating task with German native speakers. This test showed that overall, the words were equally familiar, while participants would use the diminutive forms less often than the base forms.

The four stimuli were spoken by a native German speaker with phonetic training. Several repetitions of each stimulus were recorded in order to guarantee natural variation among both standards and deviants, and to trigger a certain amount of abstraction from the standards (cf. Phillips et al., 2000). The stimuli were subsequently digitized at $16 \mathrm{bit}$, with a sampling rate of $44.1 \mathrm{kHz}$. From these recordings, we selected exemplars with similar pitch contours and energy shapes. Loudness was normalized relative to the maximum peak (95\%). Consonantal onsets of all four words (i.e. [ $\mathrm{t}$ ], duration: $260 \mathrm{~ms}$ ) were cross-spliced with the individual word endings [ok], [œkçen], [of] and [œfçen], such that we obtained four different exemplars of each word. The initial stem fragments for Experiment 1 were construed by removing the consonantal offsets of each word form. The cutting was done at zero crossings in the middle of the original vowel using the phonetic software application PRAAT (Boersma \& Weenink, 2007). The vowels in the initial fragments were lengthened in order to obtain audible and natural sounding short vowels (all durations: $70 \mathrm{~ms}$ ). Thus, all initial stem fragments were $330 \mathrm{~ms}$ long. Their endings and beginnings were smoothed by $10 \mathrm{~ms}$ fading ramps. The acoustic details of all stimuli for Experiments 1 and 2 are given in Tables 1 and 2.

We distributed the four different standard-deviant conditions into four blocks (i.e. Stock and Stoff in the standard Sto context: [Stock $]_{/ \text {Sto/, }}[\text { Stoff }]_{/ S t o /}$; Stock and Stoff in the standard Stö context: [Stock $]_{/ \text {Stö/, }}$

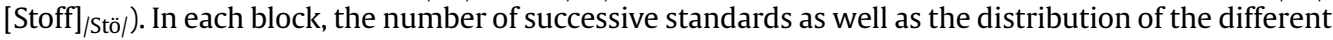
stimuli exemplars varied randomly. There were at least 4 and at most 9 successive standards. Each block comprised 438 standards $(P=0.81)$ and 104 deviants $(P=0.19)$. One trial lasted for $1200 \mathrm{~ms}$, and the total duration of one block was about $15 \mathrm{~min}$. The ISI between two successive standards was $870 \mathrm{~ms}$ on average. Since the ISI between a deviant and a standard was always smaller, standards immediately following a deviant were consistently excluded from averaging.

Table 1

Acoustic characteristics of initial fragments (rows 1 and 2, Experiment 1), singular (rows 3 and 4, Experiments 1 and 2 ) and diminutive stems (rows 5 and 6, Experiment 2). Standard errors of the mean are given in parentheses.

\begin{tabular}{lllllllll}
\hline Word & $\begin{array}{l}\text { Word } \\
\text { duration } \\
{[\mathrm{ms}]}\end{array}$ & $\begin{array}{l}\text { Word } \\
\text { intensity } \\
{[\mathrm{dB}]}\end{array}$ & $\begin{array}{l}\text { Vowel } \\
\text { duration } \\
{[\mathrm{ms}]}\end{array}$ & $\begin{array}{l}\text { Vowel } \\
\text { intensity } \\
{[\mathrm{dB}]}\end{array}$ & $\begin{array}{l}\text { Vowel } \\
\text { pitch } \\
{[\mathrm{Hz}]}\end{array}$ & $\begin{array}{l}\text { Vowel } \\
\text { F1 } \\
{[\mathrm{Hz}]}\end{array}$ & $\begin{array}{l}\text { Vowel } \\
\text { F2 } \\
{[\mathrm{Hz}]}\end{array}$ & $\begin{array}{l}\text { Vowel } \\
\text { F3 } \\
{[\mathrm{Hz}]}\end{array}$ \\
\hline$\left[\int \mathrm{t}\right.$ s] & 330 & 75 & 70 & 79 & 107 & 628 & 1031 & 2393 \\
& $(0.00)$ & $(0.21)$ & $(0.00)$ & $(0.20)$ & $(2.83)$ & $(0.46)$ & $(12.78)$ & $(16.54)$ \\
{$\left[\int \mathrm{t}[]\right.$} & 330 & 74 & 70 & 78 & 110 & 454 & 1593 & 2355 \\
& $(0.00)$ & $(0.21)$ & $(0.00)$ & $(0.35)$ & $(1.51)$ & $(3.73)$ & $(2.32)$ & $(21.69)$ \\
{$\left[\int \mathrm{t}\right.$ to $]$} & 590 & 75 & 102 & 80 & 109 & 628 & 1065 & 2349 \\
& $(0.11)$ & $(0.00)$ & $(0.00)$ & $(0.00)$ & $(0.00)$ & $(0.29)$ & $(0.29)$ & $(0.00)$ \\
{$\left[\int\right.$ tof $]$} & 609 & 76 & 123 & 82 & 105 & 629 & 997 & 2437 \\
& $(0.22)$ & $(0.00)$ & $(0.02)$ & $(0.00)$ & $(0.00)$ & $(0.63)$ & $(1.35)$ & $(0.29)$ \\
{$\left[\int\right.$ tœkçn] } & 924 & 76 & 82 & 79 & 110 & 444 & 1599 & 2298 \\
& $(0.19)$ & $(0.00)$ & $(0.00)$ & $(0.00)$ & $(0.00)$ & $(0.00)$ & $(0.00)$ & $(0.25)$ \\
{$\left[\int\right.$ tœfçn] } & 878 & 75 & 100 & 79 & 106 & 464 & 1587 & 2413 \\
& $(0.10)$ & $(0.00)$ & $(0.00)$ & $(0.00)$ & $(0.00)$ & $(0.25)$ & $(0.25)$ & $(0.29)$ \\
\hline
\end{tabular}


Table 2

Acoustic characteristics of the consonants following the stem vowels in the deviants of Experiment 1 (first two rows) and in the standards and deviants of Experiment 2. Standard errors of the mean are given in parentheses.

\begin{tabular}{llll}
\hline Consonant & Preceding vowel & Duration [ms] & Intensity [dB] \\
\hline$[\mathrm{k}]$ & {$[\mathrm{o}]$} & $241(0.16)$ & $77(0.00)$ \\
{$[\mathrm{f}]$} & {$[\mathrm{o}]$} & $234(0.20)$ & $76(0.00)$ \\
{$[\mathrm{k}]$} & {$[œ]$} & $287(0.89)$ & $74(0.01)$ \\
{$[\mathrm{f}]$} & {$[œ]$} & $284(0.01)$ & $74(0.00)$ \\
\hline
\end{tabular}

The presentation order of the 4 blocks was counter-balanced across participants, with a short break after the second block.

\subsection{Participants and procedure}

16 students of the University of Konstanz with no hearing or neurological impairment took part in the EEG study (mean age 26, 8 females). Participants gave their informed consent and were paid for their participation or received class credits.

Before EEG recording, participants were tested for their degree of right-handedness, using the Edinburgh Handedness Inventory (Oldfield, 1971). The exclusion criterion was at 80\%, but all participants performed above this threshold. We additionally tested the acceptance of an umlauted Stoff plural (i.e. "Stöffe"). For that purpose, participants had to rate the plural form on a scale from 1 (bad) to 7 (good). Three participants who rated Stöffe better than 4 were excluded from further analyses.

The stimuli were presented in a passive odd-ball setup using the software package PRESENTATION (Neurobehavioural Systems, 2002). Participants heard the stimuli over loudspeakers (TRUST Soundwave 240) next to a monitor, which was positioned approximately $2 \mathrm{~m}$ in front of them in a soundattenuated and shielded room. The monitor was used for the presentation of the electro-oculogram (EOG) triggers prior to the main experiment. During the main experiment, the monitor was used for showing a silent movie in order to keep the participants engaged and to reduce their eye movements.

The EEG was recorded from 64 electrode positions, using an electrode cap (Electrocap, Germany). Electrode positions were determined according to the 10-20 system. Horizontal and vertical eye movements were registered with additional electrodes. The ground electrode was positioned at the right cheek. $\mathrm{Cz}$ was used as a reference. An additional electrode was attached to the neck. Recordings were made with a sampling rate of $256 \mathrm{~Hz}$. Electrode impedances were kept below $5 \mathrm{k} \Omega$. Electrical signals were amplified with an ANT-amplifier, type porti-S 64 (Advanced Neuro Technology, Enschede, $\mathrm{NL}$ ) and the recording was done with the ANT-software COGNITRACE (Advanced Neuro Technology, Enschede, $\mathrm{NL}$ ), using an additional pre-amplification gain of 1.0.

\subsection{Data analysis and processing}

Raw data were corrected for horizontal and vertical eye movements as well as for blinks, using the method proposed by Berg and Scherg (1994) with the software package BESA (MEGIS, 2004). The averaging included the interpolation of bad channels, selected by a prior visual data inspection. Standard and deviant epochs were averaged including a pre-stimulus base-line of $100 \mathrm{~ms}$. Artifact rejection was based on an amplitude threshold of $75 \mu \mathrm{V}$, a gradient threshold of $60 \mu \mathrm{V}$ and a low signal threshold of $0.032 \mu \mathrm{V}$. Standard epochs immediately preceded by deviant epochs as well as the first two epochs of each experimental block were also excluded from averaging. At most, $15 \%$ of standard or deviant epochs were discarded based on these criteria, leaving between 90 and 104 deviants, and between 375 and 438 standards per subject.

Averaged data were re-referenced against the linked mastoids and base-line corrected over the prestimulus interval (100 ms). Further, the data were filtered with a symmetrical $1 \mathrm{~Hz}$ high-pass filter and a symmetrical $30 \mathrm{~Hz}$ low-pass filter (both $12 \mathrm{~dB} /$ octave).

The highest negative deviant peak between 330 and 420 ms post stimulus onset was defined as the vowel MMN peak. The selection of this time window was done for the grand average across all subjects, 
and was motivated by the expectation to find the MMN response 100-200 ms after the deviating sound segment, i.e. after the cross-splicing point at $260 \mathrm{~ms}$. Note that the consonant MMN, occurring between 420 and 470 ms post stimulus onset (cf. Fig. 1), was absent in the context of the front vowel standard (i.e. Stö, cf. Winkler, Czigler, Jaramillo, \& Paavilainen, 1998, for an explanation of this effect). Since we were interested in the vowel mismatch only, all MMN measures are vowel-based.

The MMN latency corresponded to the time (post stimulus onset) at which the highest negative amplitude in the MMN time window occurred across the electrodes Fz, FCz, and Cz.

The MMN mean amplitude $(\mu \mathrm{V})$ was calculated in windows of 50 ms surrounding the vowel MMN peaks (i.e. $\pm 25 \mathrm{~ms}$ ) in each of the four conditions. The topographies of the MMN components varied considerably across participants. A visual inspection revealed maxima located at $\mathrm{Fz}, \mathrm{Cz}$, and $\mathrm{FCz}$ (cf. Fig. 2). For that reason, we based the subsequent analyses on these three electrodes in order to cover the maximum of the MMN in most individual participants.
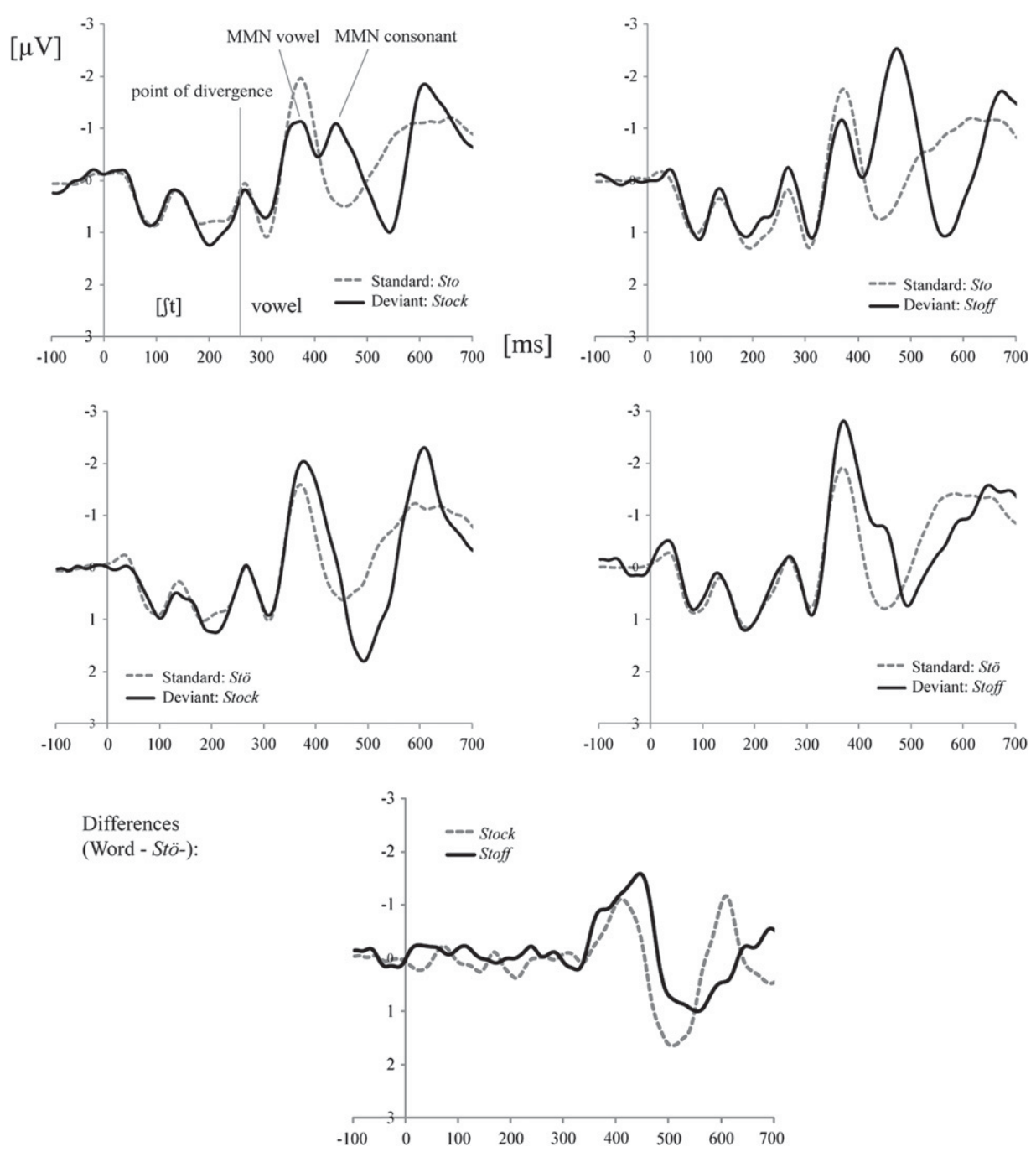

Fig. 1. Grand average ERP responses in all four experimental conditions for standards (dashed lines) and deviants (solid lines) at Fz (Experiment 1). The bottom-most difference wave forms show the differences between Stock (dotted) and Stö as well as Stoff (solid) and Stö, in the Stö context, respectively. 


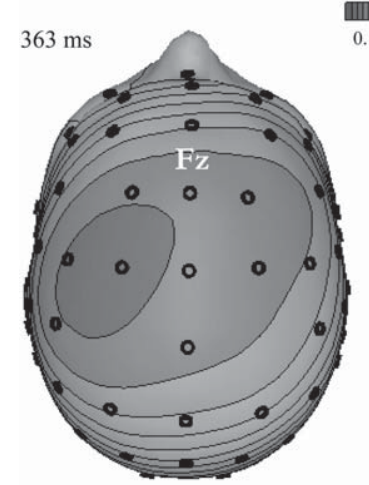

Deviant Stock in Stö context

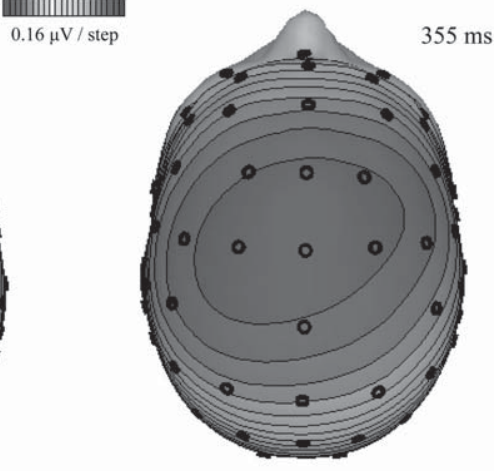

Deviant Stoff in Stö context

Fig. 2. Topographies of ERP activity in the two vowel mismatch conditions at the time point of the deviants' maximum amplitude in the MMN latency range (Experiment 1).

The LATENCY and the MEAN AMPLITUDE were used as dependent variables in the statistic analyses. The factorial designs will be specified in the results section. Wherever appropriate, Greenhouse-Geisser corrections were applied in order to reduce alpha-errors in statistical analyses.

\subsection{Results}

Fig. 1 shows the grand average data for the standards and deviants in all four experimental conditions. Further, we plotted the differences between deviant Stock and standard Stö as well as the difference between deviant Stoff and standard Stö (bottom-most panel). There is a clear differential context sensitivity of the ERPs to the same words which is mainly reflected in amplitude differences of the vowel MMN. Note that these context effects seem to be larger for the deviant Stoff than for the deviant Stock. Consonant MMNs in the context of the back vowel standards differed between deviant words Stock and Stoff, as can be seen in the top-most wave forms.

Topographies at the time of the deviants' peak amplitudes in the MMN latency range showed a main activity around Fz. Clearly, non-alternating Stoff after a front vowel standard elicited stronger and more widespread activity, as can be seen in Fig. 2 .

Reliable vowel MMNs were elicited only in the context of the front vowel standards (Stock: $t=11.00$, $p<.001,2$-tailed; Stoff: $t=19.03, p<.001 ; 2$-tailed), but not in the context of the back vowel standards (all $t \mathrm{~s}<2$ ).

The Analyses of Variance (ANOVAs) used the independent variables SUBJECT (random), DEVIANT WORD (the deviant base words Stock versus Stoff), STANDARD vowel (the vowel in the standards Sto and Stö (i.e. [o] and [œ]) and elEctrode (Fz, Cz, FCz). Additionally, all possible interaction terms were included in the analyses.

The ANOVA for the MMN latency showed no significant main effects (STANDARD VOWEL: $F(1,12)=.04$, Mse $=1489.61, p<.85$; DEVIANT WORD: $F(1,12)=.02$, Mse $=842.45, p<.90$; ELECTRODE: $F(2,24)=.58$, Mse $=74.55, p<.57, \epsilon=.96)$. There was also no interaction of STANDARD VOWEL $\times$ DEVIANT WORD $(F(1$, $12)=2.28$, Mse $=277.90, p<.16$ ). Although not legalized in this case, we calculated post-hoc tests to ensure that a difference seen in the data are indeed meaningless. These calculations revealed that the latency of Stoff in the Stö condition was significantly earlier than the latency of Stock in the Stö condition $(t=2.44, p<.03,95 \% \mathrm{CI}$ difference: 15.23$)$.

The mean amplitude ANOVA revealed a significant main effect for STANDARD VOWEL, reflecting higher MMN amplitudes in the Stö than in the Sto condition $(F(1,12)=47.47$, Mse $=2.70, p<.001)$. The factor ELECTRODE was not significant $(F(2,24)=.58$, Mse $=.33, p<.58, \epsilon=.55)$. There was also no DEVIANT WORD effect $(F(1,12)=.61$, Mse $=1.56, p<.44)$, but the interaction STANDARD VOWEL $\times$ DEVIANT WORD was significant $(F(1,12)=5.68$, Mse $=1.20, p<.04)$. Planned comparisons showed that in the context of the Sto 
standard, the mean amplitudes did not differ between the deviants Stock and Stoff $(t=1.05, p<.31)$, but if the standard was Stö, Stoff elicited significantly higher amplitudes than Stock $(t=2.32, p<.04$, 95\% CI difference: 1.59 , see Table 3 ).

The focus on the fronto-central electrode sites was justified on the one hand by the standards in the field (cf. Näätänen et al., 2007; Winkler, 2007). On the other hand, we calculated an omnibus-test, i.e. comprising all 62 electrodes in the ELECTRODE factor which turned out to show a significant DEVIANT WORD $\times$ STANDARD VOWEL $\times$ ELECTRODE interaction. There was a main effect of STANDARD VOWEL $(F(1,12)=18.23$, Mse $=14.36, p<.01)$. Whereas the interaction with DEVIANT WORD was not significant $(F(1,12)=3.19$, Mse $=8.55, p<.11)$, the interaction DEVIANT WORD $\times$ STANDARD VOWEL $\times$ ELECTRODE reached significance $(F(61$, $732)=4.07$, Mse $=1.42, p<.01, \varepsilon=.06$ ). This suggested that the amplitude effect for Stoff depended on electrode location and was, as seen in Fig. 2, more pronounced at frontal and central areas.

Visual inspection of the wave forms led us to test whether the amplitude differences occurred already at the onset of deviance (i.e. at $260 \mathrm{~ms}$ ). The ANOVA was based on a window of $50 \mathrm{~ms}$ width, and included the same factors as described above. There were neither main effects nor interactions (all Fs $<3)$.

\subsection{Discussion}

The results of Experiment 1 showed reliable vowel MMNs if the deviant vowel differed in place of articulation from the standard vowel, i.e. if the standard vowel was front and the deviant vowel was back. Additionally, there was a striking asymmetry in the MMN response to Stoff as compared to Stock if the standard was Stö: Non-alternating Stoff yielded significantly higher vowel MMN amplitudes than alternating Stock. It appeared that on top of the acoustic difference between [॰] and [œ], other, potential higher-order processes, modulated the MMN in these cases.

We additionally found consonant-related MMNs when there was no vowel change between standards and deviants (Fig. 2, cf. Czigler \& Winkler, 1996; Winkler et al., 1998). The responses differed between Stock and Stoff. We do not want to focus on these differences, but we conjecture that the effect may be driven by the earlier availability of the acoustic content of the word-final consonants: While the stridency of [f] began shortly after the vowel, the stop burst of [k] was separated from the vowel offset by approximately $100 \mathrm{~ms}$. An intensity-based explanation of the effect, on the other hand, is rather unlikely, since intensity differences between the two consonants were negligible ([f] in Stoff: $76 \mathrm{~dB}$; [k] in Stock: $77 \mathrm{~dB}$, cf. Table 2).

With regard to the vowel MMN, we suggest that the higher MMN amplitude elicited by Stoff in the front vowel context is due to "priming". Non-alternating Stoff as deviant is a truly "novel" stem in this condition. Note that the initial standard fragment Stö is likely to activate a full stem (e.g. Stöffchen). There is behavioral evidence that word beginnings indeed activate their corresponding and matching whole words. This has been shown in so-called fragment priming experiments, where Stö would facilitate the recognition of Stöffchen (cf. Cooper, Cutler, \& Wales, 2002; Cutler \& van Donselaar, 2001; Friedrich, Kotz, Friederici, \& Gunter, 2004; Marslen-Wilson, 1990; Soto-Faraco, Sebastian-Galles, \& Cutler, 2001; Spinelli, Segui, \& Radeau, 2001). Thus, it seems that the standard Stö in our experiment activated actually existing diminutive stems Stöckchen or Stöffchen. While the front vowel fragment Stö has an allomorphic relation to alternating Stock due to its plural umlaut, this relation is not given for Stoff since it does not alternate. Thus, Stoff, but not Stock, was related to a different stem than that activated by the standard Stö. As a result, Stoff elicited a stronger MMN response than Stock, because it

Table 3

Mean amplitudes and latencies in Experiment 1 at Fz (SEM = standard error of the mean).

\begin{tabular}{lll}
\hline$[\text { DeVIANT }]_{\text {/TANDARD/ }}$ & MeAn AMPLITUDE \pm SEM $[\mu \mathrm{V}]$ & MeAN LATENCY \pm SEM $[\mathrm{ms}]$ \\
\hline$[\text { Stock }]_{\text {Sto/ }}$ & $-1.01 \pm 0.40$ & $362 \pm 3.97$ \\
{$[\text { Stoff }]_{\text {Sto/ }}$} & $-0.79 \pm 0.52$ & $363 \pm 6.76$ \\
{$[\text { Stock }]_{\text {Stö/ }}$} & $-1.80 \pm 0.34$ & $363 \pm 6.60$ \\
{$[\text { Stoff }]_{\text {Stö/ }}$} & $-2.39 \pm 0.35$ & $355 \pm 6.26$ \\
\hline
\end{tabular}


was novel and not primed by the standard. We will show how this relates to current approaches of lexical representation and processing in General Discussion.

A consequence of our interpretation is that we would expect the same results if we presented the full diminutive forms as standards. This is what we did in Experiment 2. In addition, we were interested how the results of Experiment 1 relate to the study of Eulitz and Lahiri (2004) with the single vowels $[0]$ and $[\varnothing]$. We mirrored their odd-ball paradigm in distributing diminutive and non-diminutive forms over standard and deviant positions such that we were able to compare across the same acoustic stimuli.

\section{Experiment 2}

Experiment 2 was setup in order to test whether the MMN asymmetry of Experiment 1 would also hold if we used base form-diminutive pairs in a fully crossed passive odd-ball paradigm, i.e. where each of the four words Stock, Stoff, Stöckchen and Stöffchen occurred in standard and deviant position. We are then able to subtract standard responses from deviant responses based on the same word. As a consequence, we avoid consonant MMNs in this design, since the consonants preceding the stem vowels are always identical in standard and deviant position. If the effect we found in Experiment 1 is in fact based on priming, we expect to find higher vowel MMN amplitudes for the non-alternating deviant Stoff in the context of Stöffchen.

\subsection{Materials}

The four test stimuli Stock, Stoff, Stöckchen and Stöffchen were divided into four blocks. The first

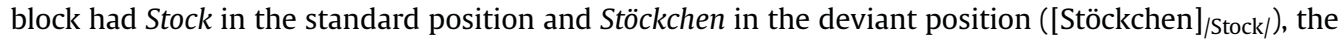
second block had Stoff in the standard position and Stöffchen in the deviant position ([Stöffchen]/Stoff/), while the third and fourth block contained the reversed pairs, i.e. [Stock $]_{/ \text {Stöckchen/ }}$ and $[\text { Stoff }]_{/ \text {Stöffchen/, }}$, respectively. Standard-deviant pairs always involved the opposition between a front ([œ]) and a back vowel ([0]).

In each block, the number of successive standards as well as the distribution of the different stimuli exemplars varied randomly. There were at least 4 and at most 9 successive standards. Each block comprised 438 standards $(P=0.81)$ and 104 deviants $(P=0.19)$. All trials lasted for $1500 \mathrm{~ms}$.

Based on our stimuli durations (cf. Table 1), the ISIs varied between an average of $900 \mathrm{~ms}$ for the base form standards and an average of $600 \mathrm{~ms}$ for the diminutive standards. Again, we excluded standards immediately following deviants from averaging. The total duration of one block was about 15 min. The presentation order of the four blocks was permutated and counter-balanced across participants, with a short break after the second block.

\subsection{Participants and procedure}

16 Right-handed students of the University of Konstanz with no hearing or neurological impairments took part in the EEG study (mean age 24, 8 females). Participants gave their informed consent and were paid for their participation.

The stimuli were presented as described in Experiment 1.

The EEG was recorded from the same 64 electrode positions as in Experiment 1, using an electrode cap (Electrocap, Germany). Horizontal and vertical eye movements were registered with additional electrodes. The ground electrode was positioned at the right cheek. $\mathrm{Cz}$ was used as reference. An additional electrode was attached to the neck. Recordings were made with a sampling rate of $250 \mathrm{~Hz}$. Electrode impedances were kept below $5 \mathrm{k} \Omega$. The electrical signals were amplified with a SynAmp amplifier (Neuroscan Compumedics) and recorded with the software NeuroScan ACQUIRE (Compumedics, 2004). After the EEG recording, the electrode locations were digitized with a POLHEMUS digitiser (Polhemus Colchester, VT, USA).

Before EEG recording, handedness and acceptance of Stöffe-plurals were tested in the same way as in Experiment 1. Three participants who rated Stöffe better than 4 were excluded from further analyses. 


\subsection{Data analysis and processing}

Raw data were treated in the same way as in Experiment 1. The artifact rejection (again based on an amplitude threshold of $75 \mu \mathrm{V}$, a gradient threshold of $60 \mu \mathrm{V}$ and a low signal threshold of $0.032 \mu \mathrm{V}$ ) led to an exclusion of more than $15 \%$ standards or deviant epochs in three subjects. These subjects were excluded from further analyses, resulting in 10 participants for the final data analyses. Again, we had a range of 90-104 deviants, and 375-438 standards per subject.

Averaged data were again re-referenced against the linked mastoids and base-line corrected using a $100 \mathrm{~ms}$ pre-stimulus interval.

From the averaged standard and deviant wave forms, the difference between each word in the deviant and in the standard condition was calculated. This ensured that the difference wave forms were based on the same acoustic tokens.

Based on the grand average $(N=10)$ of these difference wave forms, the highest negative peak between 410 and 460 ms post stimulus onset was defined as the vowel MMN peak. This window was applied to all subjects. No consonant MMN was expected.

The topographies of the MMN components again varied considerably across participants. Thus, we based all subsequent analyses on $\mathrm{Fz}, \mathrm{Cz}$, and $\mathrm{FCz}$, in order to cover the maximum of the MMN in most individual participants (cf. Fig. 4).

\subsection{Results}

Fig. 3 illustrates the grand average of the standard and deviant responses across all experimental conditions, as well as the corresponding difference wave forms. MMNs were reliable, as reflected in significant amplitude differences in the MMN time window for each condition (Stock - Stöckchen: $t=4.5, p<.01$; Stoff - Stöffchen: $t=2.5, p<.05$; Stöckchen - Stock: $t=10.89, p<.001$; Stöffchen - Stoff: $t=13.50, p<.001$; all two-tailed). In the non-subtracted wave forms, base form deviants peaked later than their corresponding standards in the MMN window between 410 and $460 \mathrm{~ms}$. While this also held for the deviant Stöckchen for which we consistently considered the second of the bimodal peak as the MMN, the deviant Stöffchen peaked slightly earlier. Crucially, Stoff as deviant elicited a higher vowel MMN amplitude than Stock, which is especially visible in the difference wave form (bottom-most right).

Scalp topographies again showed most activity around Fz, and more widespread activity for the deviant Stoff (cf. Fig. 4).

ANOVAs used the independent variables SUBJECT (random), wORD (the deviant base words Stock versus Stoff), vowEL (the stem vowel in the deviants Stock, Stoff, Stöckchen and Stöffchen, i.e. [o] versus [œ]) and Electrode $(\mathrm{Cz}, \mathrm{Fz}, \mathrm{FCz})$. Additionally, all possible interaction term were included in the analyses. Greenhouse-Geisser adjustments were applied whenever appropriate.

The latency ANOVA showed that there was no DEVIANT WORD $(F(1,9)=1.27$, Mse $=2669.63, p<.13$, vowel $(F(1,9)=0.62$, Mse $=354.37, p<.83)$, or electrode effect $(F(2,18)=1.16$, Mse $=42.42, p<.12$, $\epsilon=.57)$ but the interaction of vowel and word was significant $(F(1,9)=5.33$, Mse $=669.04, p<.05)$. Crucially, the latency of the deviant Stöffchen significantly differed from the latency of the deviant Stöckchen ( $t=3.04, p<.02$, 95\% CI difference: 39.52). On average, Stöffchen peaked $21 \mathrm{~ms}$ earlier than Stöckchen. On the other hand, the conditions $[\text { Stock }]_{/ \text {Stöckchen/ }}$ and $[\text { Stoff }]_{/ \text {Stöffchen/ }}$ did not differ in latencies $(t=.22, p<.82)$.

The mean amplitude ANOVA showed no word $(F(1,9)=1.84$, Mse $=1.64, p<.17)$, vowel $(F(1$, $9)=2.36$, Mse $=1.50, p<.21)$, or eleCtrode effect $(F(2,18)=2.18$, Mse $=.04, p<.20, \epsilon=.59)$, but a significant interaction of VOWEL $\times$ WORD $(F(1,119)=5.11$, Mse $=6.14, p<.05)$. However, while the

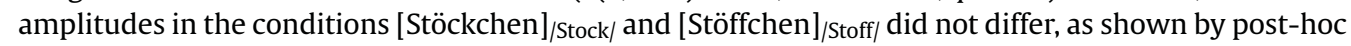
analyses $(t=.48, p<.65)$, [Stoff] $/$ Stöffchen/ elicited significantly higher amplitudes than [Stock] $/$ Stöckchen/ $(t=2.72, p<.03 ; 95 \%$ CI difference: 1.45 , see Fig. 3 and Table 4$)$.

An omnibus-test (based on 64 electrodes) also revealed a significant interaction of VOWEL $\times$ WORD $(F(1$, $9)=9.39$, Mse $=5.56, p<.01$ ), as well as an clear trend for a three-way interaction of vowEL, WORD, and electrode $(F(63,567)=1.57$, Mse $=.18, p<.01)$, which did not survive Greenhouse-Geisser adjustment 

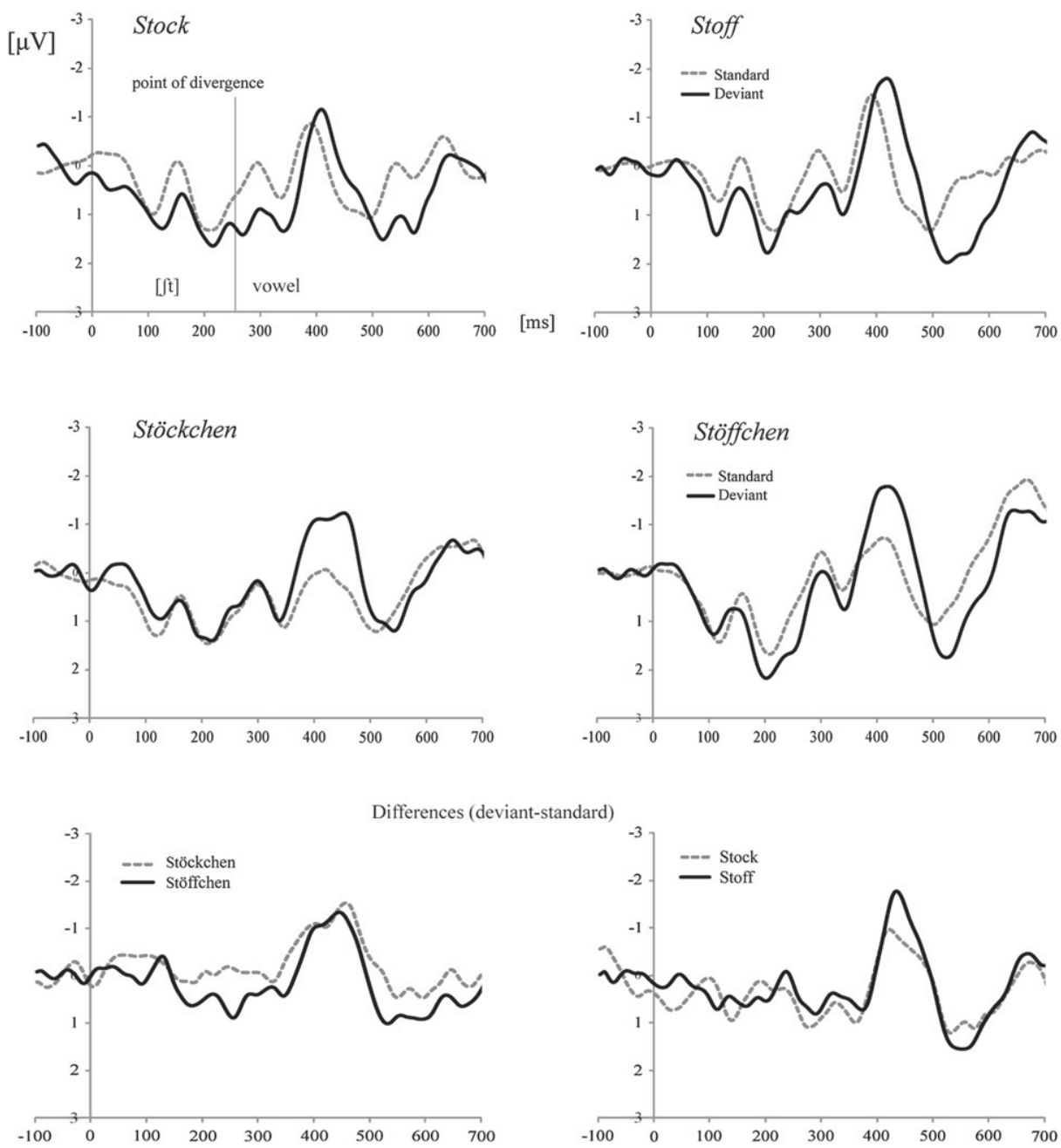

Fig. 3. Grand average ERP responses in all four experimental conditions for standards (dashed lines) and deviants (solid lines) at Fz (Experiment 2). The difference wave forms for the deviants with the vowel [œ], i.e. the diminutive deviants in the conditions

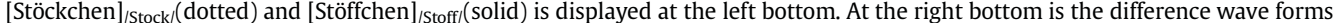

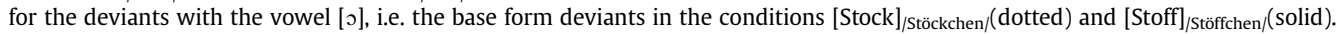

(Mse $=3.07, p<.22, \epsilon=.06$ ). Again, this test suggested that the maximum of the MMN had specific locations, which we captured well with our electrode selection.

\subsection{Discussion}

Experiment 2 replicated the MMN amplitude asymmetry of Experiment 1 in the front vowel standard context. In particular, the MMN amplitude for Stoff preceded by Stöffchen was higher than for Stock preceded by Stöckchen. Since in this experiment, stem vowels were always followed by either [k] or [f], and the opposition of standard and deviant never involved a contrast between [k] and [f], a consonant MMN immediately following the vowel MMN could be excluded (cf. Fig. 3). Thus, with respect to Winkler et al.'s (1998) study, the effect for the deviant Stoff must have truly originated in the vowel. We conjecture that the asymmetry is brought about by a "priming" effect. As mentioned before, while alternating Stock could be anticipated as an alternative to the stem presented as standard, this 
394

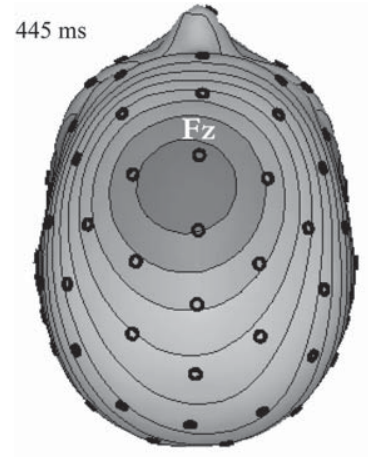

Deviant Stöckchen

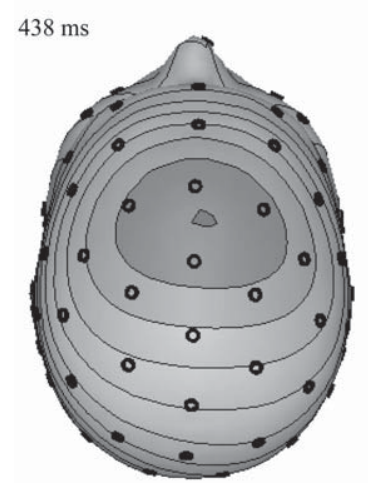

Deviant Stock

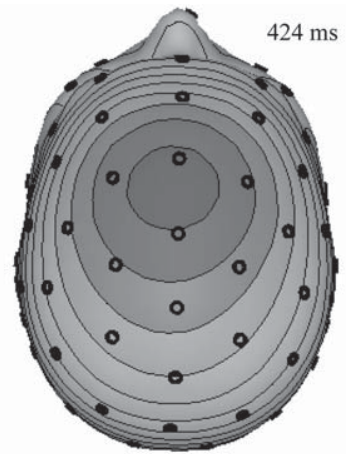

Deviant Stöffchen

$436 \mathrm{~ms}$

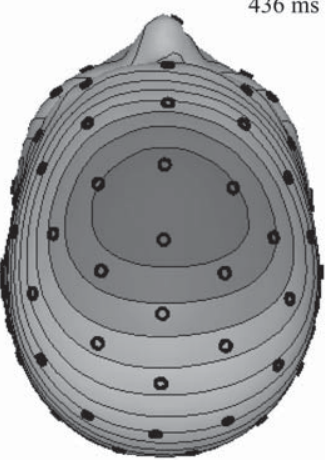

Deviant Stoff

Fig. 4. Topographies of ERP activity in the four experimental conditions at the time point of the deviants' maximum amplitude in the vowel-based MMN latency range (Experiment 2).

was not possible for non-alternating Stoff. As a result, Stoff showed a vowel-based, phonological deviance ([॰] versus [œ]) as well as a morphological deviance (alternating versus non-alternating). However, we have to refine this account, since it would not account for the pattern of the diminutive deviants, which showed no significant amplitude differences. The priming pattern is thus asymmetric. We will try account for that finding in General Discussion.

We are aware that the differences in ISIs between base form and diminutive standards could have affected the ERPs for the standards. In particular, with shorter ISIs for the diminutives, more habituation effects could have occurred, in turn causing a more positive potential for the diminutive standards (cf. Imada, Watanabe, Mashiko, Kawakatsu, \& Kotani, 1997), and a more negative potential for the base form diminutives. ${ }^{2}$ While this would enhance possible MMN contrasts, the deviants Stock and Stoff would be affected in the same way. Thus, the comparison of alternating Stock and non-alternating Stoff does not suffer from this potential confound. Further, note that based on our grand average data (Fig. 3), an ISI-based habituation asymmetry is not clearly discernible.

In the diminutive deviant cases, there was no amplitude, but rather a peak latency asymmetry. Crucially, Stöffchen as deviant elicited a significantly earlier MMN than Stöckchen. This calls into attention the results of Eulitz and Lahiri (2004) who found a similar latency asymmetry between a condition in which the standard vowel was assumed to be more specified as opposed to a condition in which the standard vowel was assumed to be less specified (in phonological terms). For our case,

\footnotetext{
2 This was brought to our attention by an anonymous reviewer.
} 
Table 4

Mean amplitudes and latencies in Experiment 2 at Fz (SEM = standard error of the mean).

\begin{tabular}{lll}
\hline$[\text { DeVIANT }]_{\text {Standard/ }}$ & MeAN Ampltude \pm SEM $[\mu \mathrm{V}]$ & MeAn LATENCY \pm SEM $[\mathrm{ms}]$ \\
\hline$[\text { Stock }]_{\text {Stöckchen/ }}$ & $-0.93 \pm 0.23$ & $438 \pm 9.07$ \\
{$[\text { Stöckchen }]_{/ \text {Stock/ }}$} & $-0.99 \pm 0.20$ & $445 \pm 8.07$ \\
{$[\text { Stoff }]_{\text {Stöffchen/ }}$} & $-1.61 \pm 0.40$ & $436 \pm 5.24$ \\
{$[\text { Stöffchen }]_{\text {/Stoff/ }}$} & $-1.02 \pm 0.26$ & $424 \pm 8.23$ \\
\hline
\end{tabular}

specificity of representation correlates of whether or not the stem vowel alternates in the plural. We turn to a more detailed discussion of this important issue in General Discussion.

\section{General discussion}

The electrophysiological assessment of the acoustic vowel oppositions between [œ] and [0] embedded in morphologically complex words has yielded intriguing asymmetries in MMN responses. In Experiment 1 as well as in Experiment 2 we found that the same acoustic vowel contrast between standard and deviant led to a stronger MMN response if the deviant vowel [o] was embedded in Stoff (cloth) than if it was embedded in Stock (stick). In Experiment 2, the front vowel stems in deviant position showed a similar pattern, but only with respect to the MMN latency. Here, [œ] embedded in the deviant Stöffchen (frazzle) elicited an earlier MMN peak than [œ] embedded in the deviant Stöckchen (little stick). Before we argue for our direction-dependent priming approach, we consider possible alternative explanations for our data.

One approach could relate the pattern of results to the phonotactic probability of our vowelconsonant sequences. Note that the initial sequences were always identical in our experiments. Hence, if phonotactic probabilities modulated the MMN responses, vowel as well as vowel-consonant probabilities should be informative, i.e. the probabilities of [0] versus [œ], [ok] versus [of] and [œk] versus [œf] might account for our data. Bonte et al. (2005) provided evidence that MMNs responses are stronger to deviants with a higher phonotactic probability than their standards, compared to the reverse case, in which deviants have a lower phonotactic probability than their standards. Considering the estimates of the phonotactic probability of vowel-[k] versus vowel-[f], there is a slightly higher probability for vowel-[f] sequences (log-values [ok] vs. [of]: 3.9 vs. 4.2; [œk] vs. [œf]: 3.3 vs. 3.6, based on CELEX, Baayen et al., 1995). However, especially in Experiment 2, the oppositions of [œk] (3.3) - [ok] (3.9) and [œf] (3.6) - [of] (4.2) yielded the same differences of 0.6. Thus, if the pattern of results were driven by differences in phonotactic probabilities, [Stock $]_{/ \text {Stöckchen/ }}$ and $[\text { Stoff }]_{/ \text {Stöffchen/ should have }}$ behaved in a symmetric way. On the other hand, single vowel probabilities differed between the front and the back vowel in German (log-values [o/॰]: 5.8, [[ø]/œ]: 4.9). This would explain general MMN differences between base form and diminutive deviants, which is not what we found. Further, Bonte et al. (2005) would predict that front vowels elicit a weaker MMN since they have smaller probabilities, a prediction which was clearly falsified by Eulitz and Lahiri (2004) in their single vowel study.

Another line of argumentation might stress the possibility that vowel asymmetries are generally rooted in perceptual asymmetries, which might be shared by humans and animals (Polka \& Bohn, 2003, for a review). The specific approach discussed in Polka and Bohn (2003), covering mostly infant data, puts forth the theory that more peripheral vowels (e.g. [o]) serve as perceptual anchors. Oppositions of non-peripheral (e.g. [œ]) and peripheral vowels are characterized in such a way that changes towards the peripheral vowels are more readily perceived than the other way around. Applied to our data, we would expect reduced MMNs for the base form deviants, which contain more peripheral vowels than the diminutive standards, as compared to cases with diminutive deviants and base form standards. Our data do not support this view. However, the explanation may hold for the Eulitz and Lahiri (2004) data, where the non-peripheral vowel [ø] elicited the greater MMN effect. Both theories seem compatible if one equals "peripheral" with "more specified" (cf. below).

Another line of alternative explanations of our results may be provided by accounts of morphological processing. Dichotomous dual route models (Pinker, 1998; Pinker \& Prasada, 1993; Pinker \& Prince, 1994) would possibly predict that the base forms Stoff and Stock are stored separately from their diminutive forms, since they involve derivational stem changes. Such a view may be also 
motivated by early experiments suggesting morphological decomposition in inflection (e.g. plural formation) but not derivation (e.g. diminutives, cf. Stanners, Neiser, Hernon, \& Hall, 1979). While inflectional processes usually operate on one lemma (one stem) and modify its morpho-syntactic properties (e.g. number in the plural), derivational processes tend to change the lexical status of the lemma (e.g. conversion from noun to verb, e.g. beauty - beautify) or lead to idiosyncrasies in meaning in German diminutives. Generally, diminutives in German appear to involve different stems than their non-diminutive counterparts. Morphologically, they are derivations rather than inflections (cf. Wurzel, 1988). For instance, Brötchen in German is not just a 'little bread' (from Brot 'bread'), but rather a special kind of pastry. Similarly, Stöffchen is not a 'small cloth' but rather a frazzle. As a result, it is reasonable to assume that inflectional stem alternants refer to one lemma (i.e. one stem), whereas derivational alternants involve two separate lemmas (stems). This is in line with the Extended Lexicalist Hypothesis of Chomsky (Chomsky, 1972), and the later Weak Lexicalist Hypothesis (Anderson, 1982, 1992; Jackendoff, 1975).

Under this view, however, we should have obtained symmetric results, since Stöckchen and Stöffchen should both contain stems separate from their base forms Stock and Stoff. As a result, the transition from standard to deviant should have been a transition from one lemma to another lemma and therefore ought to produce similar MMN responses.

More recent Dual Mechanism accounts acknowledge that morphological regularity does not necessarily align with affixation. For instance, Clahsen (2006) suggested that stems, but not necessarily the whole-form containing these stems, are stored separately if they are irregular or involve an alternation. Sonnenstuhl, Eisenbeiss, and Clahsen (1999) provided evidence that German diminutives are in fact decomposed into stems (with a front vowel) and suffix. In their priming study, diminutive primes facilitated the recognition of their base forms significantly, and independently of whether they involved a stem change (umlaut) or not. Again, according to this approach, one would predict a symmetric outcome in our experiments. If the diminutives are decomposed into stem and affix and stem access involves always the opposition of two different and separately stored entries, the MMN should have been of similar magnitude in all conditions.

Baayen et al. (1997), Frauenfelder and Schreuder (1992), and Schreuder and Baayen (1995) offer a version of the Dual Route model which includes a selection component for one or the other route. In particular, they suggest that whole-form and parsing routes are always available and operate in parallel. However, only one route will eventually dominate. Based on this idea, what we may have found in our experiments is that alternating Stöckchen triggered the decomposition route, while nonalternating Stöffchen took the whole-form route. As a result, the front vowel stem in Stöckchen was opposed to the back vowel stem of the same lemma, while the front vowel stem in Stöffchen was opposed to the back vowel stem of a different lemma. But why should there be a preference for decomposition in Stöckchen but not in Stöffchen?

Related to this question, we offer a promising account which takes into consideration the fact that Stock, but not Stoff alternates in the plural. Interestingly, the effects of Sonnenstuhl et al. (1999) were exclusively based on diminutives of which the base forms also alternate in the plural. A contrasting finding was provided by Lahiri and Reetz (2002a) who showed that priming ceased if the diminutive stems related to base forms which do not alternate in the plural. Based on the latter findings, the account presented here is framed in terms of the Featurally Underspecified Lexicon (FUL, Lahiri \& Reetz, 2002b) and also relates our findings to the vowel-based asymmetry found by Eulitz and Lahiri (2004).

Following theories of vowel harmony processes (Pulleyblank, 1986, 1988) and further vowel alternations (e.g. English vane vanity, cf. Marslen-Wilson, Tyler, Waksler \& Older, 1994; MarslenWilson \& Zhou, 1999), we conjecture that alternating stems in inflectional categories (e.g. plural) refer to one abstract stem vowel representation. This representation lacks a place of articulation information, and the vowel is said to be underspecified (Lahiri \& Marslen-Wilson, 1991; Lahiri \& Reetz, 2002b; Scharinger, 2009). In contrast, vowels of words with a non-alternating stem are always specified for their place of articulation. As a result of these assumptions, the long-term memory representation of the stem vowel in alternating Stock should differ from the representation of the stem vowel in non-alternating Stoff, although acoustically, both vowels are identical. This, in turn, should have processing consequences, based on the following considerations: According to the FUL model, phonological features are extracted from the speech signal during speech perception and then mapped 
onto their equivalents in the mental lexicon. If the feature extracted from the signal and the feature in the lexicon are the same, a full match results. If a place of articulation feature from the signal is evaluated against an underspecified place of articulation feature in the mental lexicon, a no-mismatch arises. A mismatch, finally, is characterized by a situation in which two incompatible place of articulation specifications clash. This occurs if the feature [CORONAL] is extracted from a front segment input and then mapped onto the feature [DORSAL] of a back segment.

The phonological representations of the stem vowels in Stock and Stoff correlate with our assumptions about same-stem versus separate stem storage. Non-alternating Stoff is a separate stem exactly because its stem vowel representation differs. It is specified for its place of articulation (i.e. back or dorsal), while the vowel in Stöffchen is underspecified. Hearing Stoff after Stöffchen confronts the listeners with a phonologically different stem. On the other hand, hearing Stock after Stöckchen does not confront the listener with a phonologically different stem: Their vowels are similarly underspecified. Based on the matching algorithm provided by FUL, Stoff as deviant was novel not only due to its stem representation, but also due to the [DORSAL] feature of its vowel. This feature could not be pre-activated (or primed) by the standard with a front vowel: The feature [CORONAL] extracted from the standard vowel mismatched with the feature [DORSAL]. On the other hand, Stock as deviant was not novel, and due to its underspecified stem vowel, it could be pre-activated by the standard. In this case, [CORONAL] from the standard Stöckchen was evaluated against an underspecified entry and did not lead to a mismatch.

In the diminutive deviant conditions, the standard could always pre-activate the phonological representation of the deviant, since the feature [DORSAL] never conflicted with the underspecified vowel of the diminutive stem. However, on another level of evaluation, a mismatch did occur: Recall that Eulitz and Lahiri (2004) explained their findings of a stronger MMN response for the front vowel in deviant position by referring to the opposition of the underlying vowel feature activated by the standard, and the surface feature provided by the deviant. While the standard [o] activated its underlying representation with the feature [DORSAL] and the deviant [ø] supplied the mismatching feature [CORONAL], the standard [ø] activated its underlying representation without a place of articulation feature such that the deviant [o] was a no-mismatch. The MMN was enhanced in the mismatch as opposed to the no-mismatch case. The latency pattern of Experiment 2 in this study points in a similar direction. The standard Stock presumably activated its stem with an underlyingly underspecified vowel and the deviant Stöckchen supplied the coronal feature, which did not mismatch. On the other hand, the standard Stoff activated its dorsal stem, such that the coronal feature of the deviant was a mismatch. We do not have an explanation of why this mismatch was only reflected in an earlier latency, and not in greater amplitudes of the resulting MMN. We propose, however, that the pattern of the single vowel study by Eulitz and Lahiri (2004) could not surface so easily since our complex stimuli involved more than just acoustic-phonetic and phonological processing. As mentioned before, there is good evidence that the MMN reflects processes at the level of lexical access (Pettigrew, Murdoch, Chenery, \& Kei, 2004) and beyond (Menning et al., 2005; Pulvermüller \& Shtyrov, 2006). In this vein, the phonetic-phonological effects of the single vowel studies were probably overridden by the morphological distinction of "same" versus "different stem". In the condition with back vowel stems as standards and front vowel stems as deviants, the phonological mismatch effect only surfaced as a latency difference. Note that in these conditions, the phonological features, and thereby, the morphological status of the deviant, could always be pre-activated by the dorsal standards, which had a non-conflicting relation to the underspecified diminutive stems.

While we are aware that the results of our experiments provide no direct evidence of abstract vowel representations, we think that the FUL approach provides a satisfying modeling of the asymmetric "priming" effect in Experiment 1 and 2. We can only speculate about additional phonological and morphological features of our stimuli, but for the contrasts studied here, the most crucial properties were the phonological oppositions of [CORONAL] versus [DORSAL] and the morphological oppositions of alternating versus non-alternating. Within the FUL framework, the two oppositions are linked in such a way that the non-specification of [DORSAL] allows for alternation. Of course, there is need of future work in order to flesh out more precisely how the different processing levels interact and how exactly these interactions modulate the MMN. Nevertheless, our results are a good starting point for further investigations of the interactive processes involved in spoken word recognition. 


\section{Acknowledgments}

The research for this paper was founded in part by the German Research Foundation (SFB471, Leibniz-Prize, and a grant from the ministry of Science, Research, and the Arts of Baden-Württemberg to Aditi Lahiri). We are indebted to Frans Plank, John Kingston, Claudia Friedrich and Jonas Obleser for fruitful discussion concerning relevant issues of this study. We particularly thank Barbara Awiszus, Patrick Berg, Verena Felder, Oleksiy Bobrov and Franz Zimmerer for their support in the experiments.

\section{References}

Anderson, S. R. (1982). Where's morphology? Linguistic Inquiry, 13, 571-612.

Anderson, S. R. (1992). A-morphous morphology. Cambridge: Cambridge University Press.

Baayen, H., Dijkstra, T., \& Schreuder, R. (1997). Singulars and plurals in Dutch: evidence for a parallel dual-route model. Journal of Memory and Language, 37, 94-117.

Baayen, H., Piepenbrock, R., \& Gulikers, L. (1995). The CELEX lexical database [CD-Rom]. Philadelphia, PA: Linguistic Data Consortium, University of Pennsylvania.

Berg, P., \& Scherg, M. (1994). A multiple source approach to the correction of eye artifacts. Electroencephalography and Clinical Neurophysiology, 90, 229-241.

Boersma, P., \& Weenink, D. (2007). PRAAT: doing phonetics by computer (ver. 4.6.38). Amsterdam: Institut for Phonetic Sciences. Bonte, M. L., Mitterer, H., Zellagui, N., Poelmans, H., \& Blomert, L. (2005). Auditory cortical tuning to statistical regularities in phonology. Clinical Neurophysiology, 116, 2765-2774.

Chomsky, N. (1972). Studies on semantics in generative grammar, Vol. 107. The Hague: Mouton de Gruyter.

Clahsen, H. (2006). Linguistic perspectives on morphological processing. In D. Wunderlich (Ed.), Advances in the theory of the lexicon (pp. 355-388). Berlin: Mouton de Gruyter.

Clahsen, H., Eisenbeiss, S., Hadler, M., \& Sonnenstuhl, I. (2001). The mental representation of inflected words: an experimental study of adjectives and verbs in German. Language, 77(3), 510-543.

Clahsen, H., Eisenbeiss, S., \& Sonnenstuhl-Henning, I. (1997). Morphological structure and the processing of inflected words. Theoretical Linguistics, 23, 201-249.

Compumedics. (2004). NeuroScan ACQUIRE (Version 4.2). El Paso, TX.

Cooper, N., Cutler, A., \& Wales, R. J. (2002). Constraints of lexical stress on lexical access in English: evidence from native and nonnative listeners. Language and Speech, 45, 207-228.

Cutler, A., \& van Donselaar, W. D. (2001). Voornaam is not (really) a homophone: lexical prosody and lexical access in Dutch. Language and Speech, 44, 171-195.

Czigler, I., \& Winkler, I. (1996). Preattentive auditory change detection relies on unitary sensory memory representations. NeuroReport, 7, 2413-2417.

Eulitz, C., \& Lahiri, A. (2004). Neurobiological evidence for abstract phonological representations in the mental lexicon during speech recognition. Journal of Cognitive Neuroscience, 16(4), 577-583.

Frauenfelder, U., \& Schreuder, R. (1992). Constraining psycholinguistic models of morphological processing and representation: the role of productivity. In G. Booij, \& J. van Marle (Eds.), Yearbook of morphology (pp. 165-183). Dordrecht: Kluwer.

Friedrich, C., Kotz, S. A., Friederici, A. D., \& Gunter, T. C. (2004). ERPs reflect lexical identification in word fragment priming. Journal of Cognitive Neuroscience, 16, 541-552.

Imada, T., Watanabe, M., Mashiko, T., Kawakatsu, M., \& Kotani, M. (1997). The silent period between sounds has a stronger effect than the interstimulus interval on auditory evoked magnetic fields. Electroencephalography and Clinical Neurophysiology, 102, 37-45.

Jackendoff, R. S. (1975). Morphological and semantic regularities in the lexicon. Language, 51, 639-671.

Lahiri, A., \& Marslen-Wilson, W. D. (1991). The mental representation of lexical form: a phonological approach to the recognition lexicon. Cognition, 38, 245-294.

Lahiri, A., \& Reetz, H. (2002a). Processing and representation of umlauted vowels. Paper presented at the LSA Annual Meeting, San Francisco.

Lahiri, A., \& Reetz, H. (2002b). Underspecified recognition. In C. Gussenhoven, \& N. Warner (Eds.), Laboratory phonology VII (pp. 637-677). Berlin: Mouton de Gruyter.

Marslen-Wilson, W. (1990). Activation, competition, and frequency in lexical access. In G. Altmann (Ed.), Cognitive Models of Speech Processing: Psycholinguistic and Computational Perspectives (pp. 148-172). Cambridge, MA: The MIT Press.

Marslen-Wilson, W., Tyler, L. K., Waksler, R., \& Older, L. (1994). Morphology and meaning in the English mental lexicon. Psychological Review, 101, 3-33.

Marslen-Wilson, W., \& Zhou, X. (1999). Abstractness, allomorphy, and lexical architecture. Language and Cognitive Processes, 14, $321-352$.

MEGIS. (2004). BESA: Brain Electrical Source Analysis (Version 5.1). Gräfelfing.

Menning, H., Zwitserlood, P., Schöning, S., Hihn, H., Bölte, J., Dobel, C., et al. (2005). Pre-attentive detection of syntactic and semantic errors. Neuroreport, 16(1), 77-80.

Näätänen, R. (1992). Attention and brain function. New York: Erlbaum.

Näätänen, R. (2001). The perception of speech sounds by the human brain as reflected by the mismatch negativity (MMN) and its magnetic equivalent (MMNm). Psychophysiology, 38, 1-21.

Näätänen, R., \& Alho, K. (1997). Mismatch negativity (MMN) - the measure for central sound representation accuracy. Audiology and Neurotology, 2, 341-353.

Näätänen, R., Paavilainen, P., Rinne, T., \& Alho, K. (2007). The mismatch negativity (MMN) in basic research of central auditory processing: a review. Clinical Neurophysiology, 118(12), 2544-2590. 
Neurobehavioural Systems. (2002). Presentation (Version 0.51). Albany, CA

Oldfield, R. C. (1971). The assessment and analysis of handedness: the Edinburgh inventory. Neuropsychologia, 9, 97-113.

Pettigrew, C. M., Murdoch, B. E., Chenery, H. J., \& Kei, J. (2004). The relationship between the mismatch negativity (MMN) and psycholinguistic models of spoken word processing. Aphasiology, 18(1), 3-28.

Phillips, C., Pellathy, T., Marantz, A., Yellin, E., Wexler, K., Poeppel, D., et al. (2000). Auditory cortex accesses phonological categories: an MEG mismatch study. Journal of Cognitive Neuroscience, 12, 1038-1105.

Pinker, S. (1991). Rules of language. Science, 253, 530-535.

Pinker, S. (1998). Words and rules. Lingua: International Review of General Linguistics, 106, 219-242.

Pinker, S., \& Prasada, S. (1993). Generalisation of regular and irregular morphological patterns. Language and Cognitive Processes, $1(8), 1-56$.

Pinker, S. \& Prince, A. (1994). Regular and irregular morphology and the psychological status of rules of grammar. In S. D. Lima, R. L. Corrigan, \& G. K. Iverson (Eds.), The reality of linguistic rules (pp. 321-352). Amsterdam: John Benjamins.

Polka, L., \& Bohn, O.-S. (2003). Asymmetries in vowel perception. Speech Communication, 41, 221-231.

Pulleyblank, D. (1986). Underspecification and low vowel harmony in Okpe. Studies in African Linguistics, 17, 119-153.

Pulleyblank, D. (1988). Vocalic underspecification in Yoruba. Linguistic Inquiry, 19, 233-270.

Pulvermüller, F., Kujala, T., Shtyrov, Y., Simola, J., Tiitinen, H., Alku, P., et al. (2001). Memory traces for words as revealed by the mismatch negativity. Neuroimage, 14, 607-616.

Pulvermüller, F., \& Shtyrov, Y. (2006). Language outside the focus of attention: the mismatch negativity as a tool for studying higher cognitive processes. Progress in Neurobiology, 79, 49-71.

Scharinger, M. (2009). Minimal representations of alternating vowels. Lingua, 119, 1414-1425.

Schreuder, R., \& Baayen, H. (1995). Modeling morphological processing. In L. B. Feldman (Ed.), Morphological aspects of language processing (pp. 131-154). Hillsdale, NJ: Erlbaum.

Schreuder, R., \& Baayen, H. (1997). How complex simplex word can be. Journal of Memory and Language, 37(1), 118-139.

Shtyrov, Y., \& Pulvermüller, F. (2002a). Memory traces for inflectional affixes as shown by mismatch negativity. European Journal of Neuroscience, 15, 1085-1091.

Shtyrov, Y., \& Pulvermüller, F. (2002b). Neurophysiological evidence of memory traces for words in the human brain. Cognitive Neuroscience and Neuropsychology, 13(4), 521-526.

Smolka, E., Zwitserlood, P., \& Rösler, F. (2007). Stem access in regular and irregular inflection: evidence from German participles. Journal of Memory \& Language, 57(3), 325-347.

Sonnenstuhl, I., Eisenbeiss, S., \& Clahsen, H. (1999). Morphological priming in the German mental lexicon. Cognition, 72, 203-236.

Soto-Faraco, S., Sebastián-Gallés, N., \& Cutler, A. (2001). Segmental and suprasegmental mismatch in lexical access. Journal of Memory and Language, 45, 412-432.

Spinelli, E., Segui, J., \& Radeau, M. (2001). Phonological priming in spoken word recognition with bisyllabic targets. Language and Cognitive Processes, 16, 367-392.

Stanners, R. F., Neiser, J. J., Hernon, W. P., \& Hall, R. (1979). Memory representation for morphologically related words. Journal of Verbal Learning and Verbal Behavior, 18(4), 399-412.

Wiese, R. (1987). Phonologie und Morphologie des Umlauts im Deutschen. Zeitschrift für Sprachwissenschaft, 6, $227-248$.

Wiese, R. (1996). Phonological versus morphological rules: on German umlaut and ablaut. Journal of Linguistics, 32(1), 113-135.

Wiese, R. (2000). The phonology of German. Oxford: Oxford University Press.

Winkler, I. (2007). Interpreting the mismatch negativity. Journal of Psychophysiology, 21(3-4), 147-163.

Winkler, I., Czigler, I., Jaramillo, M., \& Paavilainen, P. (1998). Temporal constraints of auditory event synthesis: evidence from ERPs. NeuroReport, 9(3), 495-499.

Winkler, I., Kujala, T., Tiitinen, H., Sivonen, P., Alku, P., \& Lehtokoski, A. (1999). Brain responses reveal the learning of foreign language phonemes. Psychophysiology, 36, 638-642.

Wurzel, W. U. (1984). Was bezeichnet der Umlaut im Deutschen? Zeitschrift für Phonetik, Sprachwissenschaft und Kommunikationsforschung, 37(6), 647-663.

Wurzel, W. U. (1988). Derivation, Flexion und Blockierung. Zeitschrift für Phonetik, Sprachwissenschaft und Kommunikationsforschung, 41(2), 179-198. 